\title{
Prenda da Mangueira
}

\author{
Keywords \\ Mango tree, Children's play, scavenger hunt, transmedia, community.
}

Prenda da Mangueira is an Alternate Reality Game (ARG) in the process of production in which uses the Mangueira Desejo project as a base to bring back a well known children's game called Boca de Forno, that consists of one of the children being the leader which will be called mãe (mom), that will be in charge of giving errands to run by the other children as fast as they can right after singing a song together led by mãe. ARGs are transmedia analogic games that gather a community together to interact and play, solving puzzles, mysteries, quests and so on. They all have a strong narrative that extends our current reality and evolves as the players' progress. The game is normally managed by their designers. The ARG's definition is quite open, but some authors agree on the use of the term transmedia "the aggregate effect of multiple texts/media artifacts" as the defining attribute of ARGs. Even being a game, designers and players tend to bring a sentiment of that not being a real game but the reality itself. As adulthood comes we start to leave behind those games we used to play as children. Each generation has their own games and to those people who lived during the times with little or no internet, the trees still had some meaning and an importance, they were either a physical point of reference and a stage for children to gather and play around its shelter. Many of our already known children's games were born, taught and learned in scenarios like that, together with a handful of nostalgic memories that are getting harder and harder to bring back due to the decreasing social contact brought by many factors of our current way of life. As Mango Tree (Mangueira Desejo) project already brings us the observation of our current reality through an alternate digital one, bringing back and setting new meanings to the city's mango trees, done over the idea of Yoko Ono's project Wish Tree which encourages us to express ourselves through the written wishes hung up on any living tree. The project's intent is to add a new expression to Mangueira Desejo project which is a new narrative that comprises the mãe (mom) played by the designers through the tree entity that brings errands for the players to run. As the base project uses trees, this project will stick to it and place physical markers on city's trees in order to let anyone with an AR ready mobile device with the app installed to play the game. 